\title{
KAPASITAS KNOWLEDGE MANAGEMENT UNTUK MENINGKATKAN KERJASAMA DAN INOVASI DALAM \\ PERUSAHAAN (Suatu Tinjauan Teoritis)
}

\author{
Basuki $^{1}$ \\ Email: $\underline{\text { msibasukidr@gmail.com }}$ \\ Rahmi Widyanti ${ }^{2}$ \\ Mursanto $^{3}$
}

\begin{abstract}
The purpose of this paper is to study the capacity of Knowledge Management in a theoretical review and aims to understand how companies can strengthen the context of the cooperative elements that exist within the organization to generate innovation. The method used in this paper is the library method based on empirical studies from the results of previous studies and literature studies.

The justification of the absorptive capacity typology for innovation efficiency processes has the potential to influence the absorption realized in new products and cause effects on internal research and development in various ways. The impact of joint ventures, supplier cooperation and customer cooperation is significant on absorption.

The implication in this paper is to extend the research to other innovation metrics as new organizational methods, new processes, new designs, or new methods of using sales funnels.

This paper considers it necessary to analyze the typology of capacities that enable managers to understand the innovation efficiency process in the context of collaboration and make better decisions. Collaboration of collaborative activities, organizational capacity and objectives in internal research and development can obtain higher innovation results.
\end{abstract}

Keywords: Knowledge management, capacity, intelectual capital, innovation, collaboration.

\section{PENDAHULUAN}

Knowledge mangement atau manajemen pengetahuan merupakan bagaimana suatu proses berbagi dari sekumpulan orang orang dari berbagai tempat yang berbeda untuk mulai saling bicara, menyampaikan ide-ide dan gagasannya yang sekarang populer dengan label learning organization. Knowledge sebagai basis dari penciptaan intellectual capital harus dibangun melalui pendekatan manajemen yang fokus kepada 
pengembangan manusia sebagai human capital. Di Indonesia memiliki SDM dengan jumlah besar, namun tetap saja tidak mampu membangun keunggulan kompetitif secara global. Inilah tantangan badan usaha di Indonesia. Proses penciptaan Knowledge organisasi terjadi karena adanya interaksi (konversi) antara Tacit Knowledge dan Explicit Knowledge melalui proses sosialisasi, eksternalisasi, kombinasi dan internalisasi dan untuk merancang system knowledge management yang dapat membantu organisasi untuk meningkatkan kinerja diperlukan empat komponen yaitu aspek manusia, proses, teknologi dan content (Basuki, 2015).

Untuk mencapai organisasi yang inovatif, maka perlu dibangun budaya knowledge sharing (berbagi pengetahuan). Keuntungan dari knowledge adalah pelakunya mampu merespon kesempatan dengan cepat. Karena organisasi merupakan jaringan dari keputusan para perumus kebijakan dan pengambilan keputusan, ia perlu dikelola agar keputusan tersebut efektif dan terintegrasi serta ada dampaknya dari keputusan tersebut.

Salah satu faktor yang mempengaruhi pemilihan strategi pada organisasi/perusahaan adalah orientasi inovasi. Orientasi inovasi menggambarkan bagaimana organisasi berinovasi dan hasilnya dapat digunakan untuk mengimplementasikan strategi.

Kemampuan perusahaan untuk berinovasi akan tergantung pada kecenderungan manajemen, formulasi strategi untuk mendukung inovasi dan konstituen sumber daya manusia yang mendukung inovasi tersebut (Rofiati, 2012).

Inovasi secara luas dipandang sebagai komponen penting dari daya saing, tertanam dalam struktur organisasi, proses, produk dan layanan di dalam sebuah perusahaan. Inovasi merupakan komponen strategi perusahaa yang sangat diperlukan karena beberapa alasan seperti menerapkan proses produksi yang lebih produktif, tampil lebih baik di pasar untuk mendapatkan reputasi positif dalam persepsi pelanggan dan pada akhirnya untuk mendapatkan keunggulan kompetitif yang berkelanjutan. (Gunday et al., 2011).

Inovasi memiliki pengaruh yang positip terhadap perekonomian dan menjadi elemen kunci dalam proses kewirausahaan. Sejumlah hasil penelitian menjelaskan bahwa inovasi memiliki hubungan yang positip terhadap kinerja perusahaan (Yildiz, et al., 2014; Ndesaulwa \& Kikula, 2016). Dengan demikian inovasi memiliki peran penting dalam pengembangan usaha dan peningkatan kinerja perusahaan. 
Dalam tulisan ini bertujuan untuk membahas bagaimana kapasitas dari daya serap knowledge management dalam upaya meningkatkan kerjasama dan inovasi dalam perusahaan berdasarkan hasil penelitian terdahulu dan studi kepustakaan.

\section{TINJAUAN TEORITIS}

\section{Membangun kapasitas Knowledge Management dan Modal Intelektual}

Berdasarkan banyak artikel yang mengacu pada kapasitas penyerapan knowledge management, menyajikan berbagai konseptual, dan sering bertentangan (Roberts, Galluch, Dinger \& Grover, 2012). Pada Januari 2017, konstruksi tersebut dikutip lebih dari 23.000 kali dalam literatur manajemen (Sumber: Google Cendekia).

Kapasitas knowledge management didefinisikan sebagai "kemampuan perusahaan untuk mengenali nilai baru, informasi eksternal, mengasimilasinya, dan menerapkannya pada tujuan komersial". Pada titik ini, tantangannya tetap bagaimana konstruksi kapasitas dapat terserap yang banyak dikutip telah dikembangkan dalam manajemen pengetahuan dan literatur modal intelektual selama 27 tahun terakhir.

Berdasarkan analisis mendalam, Mariano dan Walter (2015) menghitung hanya sembilan penelitian di mana daya serap menjadi landasan teori artikel dalam sudut pandang ini dan dua artikel berbasis teori (Andersén, 2012; Nieminen, 2005). Artikelartikel ini berpusat pada berbagai bidang, dari pembelajaran organisasi dan manajemen pengetahuan hingga kemampuan dinamis (Denford, 2013; Noblet, Simon \& Parent, 2011), jaringan (Wang \& Han, 2011) dan dampak pada inovasi (Tseng, Pai \& Hung, 2011), tetapi tidak memberikan perspektif terpadu tentang bagaimana penelitian masa depan tentang kapasitasnya harus diarahkan di bidang manajemen pengetahuan dan modal intelektual .

Seperti yang juga disarankan oleh Roberts et al. (2012), studi masa depan harus mengeksplorasi daya serap kapasitas knowledge management sebagai kemampuan lebih dari aset dan mengembangkan satu set variabel yang pada dasarnya mempengaruhi tingkat daya serap (Noblet et al., 2011).

Penelitian sebelumnya tentang manajemen pengetahuan dan modal intelektual, tulisan ini bertujuan untuk menyajikan konseptualisasi yang lebih komprehensif, jenis dan pengukuran kapasitas knowledge management sebagai konstruksi yang kompleks untuk 
memperluas pemahaman kita tentang hubungan antara kapasitas dan sumber pengetahuan. Tulisan ini juga untuk menjawab pertanyaan berikut: "kapasitas manajemen pengetahuan untuk meningkatkan kerjasama dan inovasi di perusahaan".

\section{Hubungan Antara Sumber Pengetahuan dan Kapasitas dengan Kinerja Inovasi}

Kinerja inovasi merupakan sumber fundamental keunggulan kompetitif dan dipengaruhi baik oleh asal-usul pengetahuan yang ada yang digabungkan untuk menghasilkan inovasi maupun oleh bagaimana pelaku ekonomi mencari pengetahuan baru (Rofiati, 2012, Capaldo \& Messeni, 2015).

Menurut Aribi dan Dupouët (2016) menyarankan bahwa proses menampilkan beberapa langkah umpan balik, baik di dalam dan di antara setiap fase penyerapan tidaklah selalu sejalan. Lowik dkk. (2016) menyebutkan bahwa manajer yang berusaha meningkatkan kinerja tim intensif pengetahuan disarankan untuk mengambil pendekatan holistik dan mempertimbangkan tiga serangkai kapasitas penyerapan tim: kapasitas penyerapan individu anggota tim, mekanisme yang memungkinkan dan memotivasi integrasi pengetahuan. Para penulis menunjukkan bagaimana pendekatan konfigurasional memperdalam pemahaman tentang fondasi mikro kapasitas daya serap tim terhadap pengetahuan tersebut.

Selanjutnya, Rezaei dan Darwish (2016) mengungkapkan bahwa interaksi kompleks antara anteseden kapasitas daya serap knowledge management dan menunjukkan bahwa anteseden ini bervariasi, terdiri dari proses pembelajaran eksplorasi, transformatif, dan eksploitatif. Grandinetti (2016) menggunakan konstruksi ini untuk memperjelas perbedaan antara Usaha Kecil dan Menengah (UKM) dan perusahaan besar dari sudut pandang manajemen pengetahuan. Perbedaan tersebut umumnya dikaitkan dengan fakta bahwa UKM lebih mengandalkan sumber pengetahuan eksternal. Hal ini akan terbukti jika sumber eksternal seperti itu selalu digunakan sebagai pengganti proses penciptaan pengetahuan internal, tetapi perusahaan besar juga memelihara kapasitas produksi pengetahuan internal mereka melalui saluran penyerapan pengetahuan yang sama kuatnya. 


\section{Tipologi Daya Serap Pengetahuan dalam Konteks Kerjasama untuk Efisiensi Inovasi}

Berdasarkan sudut pandang inovasi dalam ekonomi, hubungan dan kerjasama departemen penelitian dan pengembangan dapat diapresiasi sebagai proses spillover yang merupakan istilah ekonomis untuk mewakili diseminasi pengetahuan. Tidak seperti aset fisik, pengetahuan sulit untuk disesuaikan dan mudah disebarkan dalam perekonomian melalui berbagai saluran (Fukugawa, 2015).

Fukugawa (2015) menunjukkan bagaimana konsep daya serap dapat diterapkan pada pengajaran dalam bahasa Inggris sebagai saluran limpahan. Penulis menganggap bahwa kuliah adalah mode transfer pengetahuan dan siswa diasumsikan untuk mempertahankan tingkat tertentu dari kapasitas penyerapan melalui keterampilan intelektual dan linguistik yang merupakan 'kapasitas serap' mereka dan memungkinkan mereka untuk memperoleh 'pengetahuan baru' dari 'spillover pool' .

Agar peserta dapat memanfaatkan pengetahuan eksternal secara maksimal, mereka perlu mengumpulkan kapasitas penyerapan melalui pemahaman 'peserta didik' dan keterampilan linguistik mereka sendiri. Sebesar apapun spillover pool, tidak masuk akal jika pengguna tidak memiliki daya serap (Fukugawa, 2015). Setelah kita dapat memahaminya, sebagai aplikasi khas dari daya serap Cohen dan Levinthal (1990) untuk bidang tertentu dan kita dapat mengamati kapasitas itu sebagai konstruksi kolektif.

\section{METODE PENELITIAN}

Tulisan ini merupakan hasil studi kepustakan dari beberapa jurnal hasil penelitian yang berkaitan dengan knowledge management, modal intelektual dan inovasi. Metode yang digunakan adalah studi empirik dari artikel hasil penelitian dan studi kepustakaan yang dirangkum menjadi sebuah tinjauan teoritis (Basuki, 2020)

\section{PEMBAHASAN}

\section{Kapasitas Knowledge dan Kerjasama Inovasi}

Dalam perusahaan proses berbagi pengetahuan antara individu memerlukan peran yang intensif dari departemen penelitian dan pengembangan. Semakin baik peran 
departemen penelitian dan pengembangan dalam membagi pengetahuan akan semakin baik pula daya serap individu terhadap pengetahuan. Hal ini akan berdampak pula pada peningkatan inovasi dan daya saing perusahaan.

Menurut Capaldo dan Messeni (2015) bahwa hubungan departemen penelitian dan pengembangan yang berintegrasi pada pengetahuan yang jauh secara geografis dan pengetahuan yang dekat secara organisasi dalam aliansi R\&D terdapat hubungan yang negatif dengan kinerja inovasi, rentang pencarian aliansi secara positif memoderasi kedua hubungan. Para peneliti menyimpulkan bahwa perusahaan yang berpartisipasi dalam aliansi $R \& D$ harus mengintegrasikan pengetahuan yang jauh secara geografis tetapi dekat secara organisasional. Dengan demikian, perusahaan mengambil keuntungan dari keragaman dan kebaruan yang menjadi ciri pengetahuan yang jauh secara geografis, sambil mempertahankan tingkat kapasitas penyerapan relatif yang diperlukan bagi mereka untuk memahami, menginternalisasi, dan secara efektif menggunakan pengetahuan mitra dari wilayah yang berbeda.

Selanjutnya menurut Yoo, Sawyerr dan Tan (2015) menyatakan bahwa adanya efek langsung dari faktor lingkungan dan spesifikasi perusahaan serta efek moderasi dari lingkungan eksternal pada faktor spesifikasi perusahaan. Díaz-Díaz dan Saá-Pérez (2014) mengkonfirmasi bahwa jenis sumber pengetahuan yang digunakan, internal atau eksternal, merupakan keputusan penting, dan mengungkapkan bahwa perlu untuk mengidentifikasi setiap sumber yang mungkin digunakan, karena pengaruhnya terhadap inovasi dapat berbeda tergantung pada pentingnya basis pengetahuan internal. Kebijakan untuk memperbarui pengetahuan dalam rangka memperbarui kapasitas perusahaan untuk berinovasi adalah keputusan eksekutif yang penting, yang memiliki konsekuensi signifikan pada proses manajemen pengetahuan seperti yang telah dikonfirmasi oleh beberapa penulis (Fixson \& Lee, 2012; Messeni, Rotolo \& Albino, 2012; Sun , 2010).

Berkenaan dengan penggunaan sumber pengetahuan internal, temuan para penulis mengkonfirmasi bahwa daya serap kapasitas pengetahuan meningkatkan inovasi hingga titik tertentu, setelah itu efek positif ini dapat menurun. 
Dapat dikatakan bahwa perusahaan dengan kelebihan pengetahuan internal tidak memperoleh hasil inovatif yang lebih baik karena seiring waktu, perusahaan cenderung memasuki keadaan inersia dan membutuhkan sumber pengetahuan eksternal untuk memperbaharui pengetahuan mereka.

Karena "pertemuan antara pengetahuan internal yang berlebihan dan inersia organisasi dapat membuat hubungan antara kapasitas penyerapan dan inovasi perusahaan menjadi non-linear" (Díaz-Díaz \& Saá-Pérez, 2014: halaman 440).

Paulsen dan Hjertø (2014) menunjukkan bahwa otonomi individu dan kelompok, bersama dengan pengalaman individu dari kapasitas penyerapan, mendukung transfer pengetahuan antar organisasi yang saling melengkapi. Noblet dkk. (2011) menekankan peran kepercayaan dalam pertumbuhan kapasitasnya. Wang dan Han (2011) berpusat pada kondisi lingkungan dan hubungan kinerja inovasi kapasitas serap, dengan perhatian khusus pada penelitian pentingnya struktur jaringan.

Tinjauan terhadap penelitian yang lebih relevan menentukan bahwa Van der Heiden, Pohl, Mansor dan Van Genderen (2016) membedakan kapasitas serap yang “diperlukan” sebagai kemampuan dinamis. Ojo, Raman dan Chong (2016) berkonsentrasi pada "potensi kapasitas penyerapan" untuk menjelaskan faktorfaktor yang mendasari perbedaan kapasitas penyerapan individu dalam konteks tim proyek bersama.

Martelo-Landroguez dan Cegarra-Navarro (2014) meneliti pentingnya transfer pengetahuan dan proses penyimpanan/pengambilan kembali pengetahuan sebagai jembatan antara "kapasitas serap potensial" dan "kapasitas serap yang direalisasikan" dan pengaruhnya terhadap penerapan pengetahuan.

Para peneliti mengungkapkan bahwa "kapasitas daya serap pengetahuan yang direalisasikan" tidak mungkin tanpa dipupuk oleh transferensi dan penyimpanan pengetahuan baru dan oleh karena itu memerlukan pemberdayaan oleh faktorfaktor yang memfasilitasinya.

\section{Kapasitas Knowledge Management dan Tujuan Organisasi}


Hal itu dimungkinkan karena beberapa penelitian bertujuan untuk menggambarkan bagaimana kapasitasnya bekerja. Aribi dan Dupouët (2016) melanjutkan pernyataan berikutnya. Pertama, semua penulis menyajikan kapasitas serap sebagai proses yang terungkap dari waktu ke waktu dan yang mungkin melibatkan aktor yang berbeda dari perusahaan. Kedua, terlepas dari perbedaan antara model, setiap orang dapat membedakan tiga fase utama: eksplorasi, transformasi, dan eksploitasi.

Berdasarkan manajemen pengetahuan dan gagasan kapasitas serap organisasi sebagai kapasitas meta-rutin (Paulsen \& Hjert, 2014; Van der Heiden et al., 2016) dan dikelilingi dalam konteks kerjasama, tipologi kapasitas serap diwakili perlu dihubungkan dengan pengaturan tujuan organisasi. Ketika sumbernya eksternal, kapasitas penyerapan memungkinkan karyawan memperkenalkan data penting dan melacak informasi potensial di sekitar batasnya. Untuk memperoleh suatu kapasitas realisasi diperlukan suatu kapasitas potensial. Semakin banyak potensi dapat berarti semakin besar persentase realisasinya. Perusahaan kapasitas serap yang berkinerja baik mengubah potensinya dalam tindakan yang direalisasikan.

Selanjutnya, pekerja perusahaan harus dengan jelas mengidentifikasi apa tujuan yang diperlukan untuk meningkatkan proyek R\&D internal. Kami menganggap bahwa perusahaan ketika belajar adalah proses yang tidak menguntungkan kecuali jika dikaitkan dengan instrumen untuk meningkatkan. Sementara pembelajaran adalah proses akumulatif tanpa akhir, daya serap yang berguna tergantung pada penetapan tujuan. Kapasitas daya serap pengetahuan selesai ketika tujuannya terpenuhi dan dengan demikian lebih banyak pembelajaran tidak diperlukan.

Berdasarkan pembahasan diatas, maka dapat disarikan beberapa variabel yang dapat dijadikan ukuran apabila akan dijadikan penelitian lebih lanjut.

Variabel tak bebas. Variabel terikat dalam penelitian ini adalah inovasi produk organisasi, yang diukur dari aliran output. Variabel (Innovation Efficiency) diukur sebagai banyaknya produk baru yang diperoleh perusahaan setiap tahunnya.

Variabel penjelas. Sumber Eksternal Sekitar Kegiatan Kerjasama diukur dengan tiga variabel. Variabel pertama meliputi pendirian perusahaan patungan teknologi (Joint Ventures). Variabel berikutnya mencerminkan pembentukan perjanjian kerjasama teknologi perusahaan dengan pelanggannya (Kerjasama Pelanggan) atau 
dengan pemasoknya (Kerjasama Pemasok). Tindakan ini tidak memerlukan komitmen dan keterlibatan yang tinggi dari perusahaan seperti yang dilakukan oleh usaha patungan. Upaya R\&D Internal diukur sebagai logaritma dari pengeluaran R\&D internal setiap tahun. Dua variabel lainnya diperoleh dari analisis faktor

\begin{tabular}{|c|l|}
\hline Variabel & Deskripsi \\
\hline Inovasi efisiensi & Inovasi: jumlah produk baru yang diperoleh perusahaan di setiap tahun. \\
\hline Tujuan organisasi & Upaya R\&D internal: logaritma dari pengeluaran R\&D internal setiap tahun. \\
\hline
\end{tabular}

konfirmatori. Faktor pertama, Kewaspadaan Teknologi sebagai ukuran Potensi Daya Serap, terdiri dari tiga item yang mencerminkan evaluasi teknologi alternatif oleh perusahaan, evaluasi perubahan teknologi dan kontrak konsultan luar sebagai mekanisme untuk memperoleh informasi tentang teknologi. Komponen Tabel 2 mencapai $78,1 \%$ dari total varians yang dijelaskan.

Faktor kedua, Manajemen Teknologi sebagai ukuran Realized Absorptive Capacity, meliputi keberadaan manajemen atau komite teknologi suatu perusahaan, penyusunan rencana dan pengukuran hasil yang diperoleh dalam proses manajemen ini. Komponen Tabel 3 mencapai 82,5\% dari total varians yang dijelaskan. 


\begin{tabular}{|l|l|}
\hline $\begin{array}{l}\text { Kapasitas } \\
\text { penyerapan } \\
\text { potensial }\end{array}$ & $\begin{array}{l}\text { Kewaspadaan teknologi: Dimensi faktor yang terdiri dari tiga } \\
\text { item yang mencerminkan evaluasi teknologi alternatif, evaluasi } \\
\text { perubahan teknologi dan kontrak konsultan luar di setiap } \\
\text { tahun. }\end{array}$ \\
\hline $\begin{array}{l}\text { Kapasitas } \\
\text { penyerapan } \\
\text { yang } \\
\text { direalisasikan }\end{array}$ & $\begin{array}{l}\text { Manajemen teknologi: Dimensi faktor yang mencerminkan keberadaan } \\
\text { manajemen atau komite teknologi, penyusunan rencana dan ukuran hasil } \\
\text { yang diperoleh dalam proses manajemen ini setiap tahun. }\end{array}$ \\
\hline
\end{tabular}

\begin{tabular}{|l|l|}
\hline Kegiatan koperasi & $\begin{array}{l}\text { Usaha patungan: pendirian perusahaan dari usaha teknologi bersama. } \\
\text { Kerjasama pelanggan: pembentukan perjanjian kerjasama } \\
\text { teknologi dengan pelanggannya di setiap tahun. } \\
\text { Kerjasama pemasok: pembentukan perjanjian kerjasama teknologi } \\
\text { dengan pemasoknya di setiap tahun. }\end{array}$ \\
\hline \multirow{2}{*}{ Kontrol } & Ukuran: logaritma karyawan perusahaan. \\
& Umur: jumlah tahun sejak pendirian perusahaan. \\
& ROA: pengembalian aset perusahaan di setiap tahun. \\
& Lokasi: nilai 1 jika perusahaan bersaing di pasar nasional atau \\
& internasional, dan 0 jika tidak. \\
& Pasar stabil: nilai 1 jika perusahaan merespons pertanyaan \\
tentang pasar yang stabil, dan 0 jika pasar berkembang. \\
Pasar dalam resesi: nilai 1 jika perusahaan merespons secara positif \\
tentang pasar resesif, dan 0 jika tidak. \\
Intensitas teknologi industri: empat variabel Dummy yang \\
mewakili intensitas teknologi industri (rendah, sedang-rendah, \\
sedang-tinggi, tinggi). \\
\\
\end{tabular}

Studi ini mengungkapkan hasil teoritis penting yang memberikan kontribusi signifikan untuk memperjelas pertanyaan tentang pengaruh jenis daya serap terhadap efisiensi inovasi. Pertama, berkaitan dengan penggunaan sumber pengetahuan eksternal, temuan makalah mengkonfirmasi bahwa hubungan antara kegiatan kerjasama dan daya serap perusahaan. Lebih lanjut, sementara kerjasama pemasok dan pelanggan adalah tindakan yang relevan untuk meningkatkan upaya $R \& D$ internal, usaha patungan dan kerja sama pelanggan penting bagi pertumbuhan produk baru. Di sisi lain, usaha patungan memiliki pengaruh negatif dan signifikan terhadap tujuan organisasi dalam R\&D internal dan kerjasama pemasok tidak berpengaruh signifikan terhadap inovasi.

Kedua, daya serap potensial, yang diukur sebagai kewaspadaan teknologi dalam penelitian ini, merupakan elemen penting dari upaya litbang internal ketika daya serap yang direalisasikan. Selain itu, muncul sebagai pengaruh yang signifikan dan positif 
pada model inovasi. Ketiga, realisasi daya serap, terukur sebagai manajemen teknologi dalam studi ini, menangkap semua kekuatan penjelas dari potensi daya serap ketika upaya litbang internal diperkirakan secara globalTerakhir, temuan penelitian ini perlu diperhatikan karena didasarkan pada model data panel dan konsisten dengan penelitian sebelumnya, terkait dengan daya serap merupakan instrumen mediasi antara keragaman aliansi teknologi dan inovasi (Lucena \& Roper, 2016), yang signifikan interaksi antara sumber pengetahuan eksternal dan internal pada produk baru (Díaz-Díaz \& Saá-Pérez, 2014), dampak positif yang tinggi dari kegiatan R\&D internal (Sánchez, Rosell \& García, 2013), proses inovasi bukanlah fenomena sektoral (Segarra -Ciprés et al. 2012), pentingnya variabel ukuran (Revilla \& Fernández, 2012), R\&D sebagai penentu inovasi, signifikansi statistik yang rendah dari variabel usia (Beneito et al., 2011) dan efek positif dari aset pengetahuan teknologi pada proses inovasi (Diaz, 2014; Nurcahyo, 2020).

\section{KESIMPULAN}

Mengingat wawasan tersebut dari sudut pandang manajemen pengetahuan, studi ini menganggap perlu untuk menganalisis tipologi kapasitas serap yang dapat memungkinkan manajer untuk memahami proses efisiensi inovasi dalam konteks kerjasama dan, oleh karena itu, membuat keputusan yang lebih baik. Pertemuan kegiatan kerjasama, daya serap perusahaan dan tujuan organisasi dalam R\&D internal akan memperoleh hasil inovatif yang lebih tinggi.

Perusahaan membutuhkan sumber pengetahuan eksternal untuk memperbaharui pengetahuan mereka. Oleh karena itu, mereka perlu melihat ke luar batas perusahaan dan, sebagai titik akhir, mereka membutuhkan pengalaman dan sumber daya dalam R\&D internal untuk dapat mengembangkan lebih banyak inovasi. Makalah ini menegaskan bahwa potensi dan realisasi kapasitas serap berhubungan dan menyebabkan efek dengan cara yang beragam. Kami memberikan bukti bahwa jenis kapasitas penyerapan dan upaya $R \& D$ internal berfungsi sebagai mekanisme mediasi antara kegiatan koperasi dan kinerja inovatif.

\section{DAFTAR PUSTAKA}


Andersén, J. (2012). Protective capacity and absorptive capacity: Managing the balance between retention and creation of knowledge-based resources.Learning Organization, 19(5), 440-452. https://doi.org/10.1108/09696471211239730

Aribi, A., \& Dupouët O. (2016). Absorptive capacity: A non-linear process. Knowledge Management Research \& Practice, 14, 15-26. https://doi.org/10.1057/kmrp.2014.17

Basuki, 2015, Pengaruh Praktik Sumber Daya Manusia Strategik Dan Knowledge Management Terhadap Kinerja Organisasi, Al Kalam Jurnal Komunikasi Bisnis dan Manajemen, Vol.2 No.4 Juli 2015.

Basuki, 2020. Pengantar Metode Penelitian Kuantitatif, Penerbit Media Sains Indonesia, Bandung.

Beneito, P., Rochina, M., \& Sanchis, A. (2011). La experiencia en I+D como factor determinante de la innovación. Papeles de Economía Española, 127, 89-104.

Capaldo, A., \& Messeni, A. (2015). Origins of knowledge and innovation in R\&D alliances: a contingency approach. Technology Analysis \& Strategic Management, 27(4), 461-483. https://doi.org/10.1080/09537325.2015.1011612

Díaz-Díaz, NL, \& Saá-Pérez, P. (2014). The interaction between external and internal knowledge sources: An open innovation view. Journal of Knowledge Management, 18(2), 430-446. https://doi.org/10.1108/JKM-07-2013-0257

Grandinetti, R., (2016). Absorptive capacity and knowledge management in small and medium enterprises. Knowledge Management Research \& Practice, 14, 159168.

Hagemeister, M., \& Rodríguez-Castellanos, A. (2010). Organisational capacity to absorb external R\&D: industrial differences in assessing intellectual capital drivers. Knowledge Management Research \& Practice, 8(2), 102-111.

Lowik, S., Kraaijenbrink, J., \& Groen, A. (2016). The team absorptive capacity triad: A configurational study of individual, enabling, and motivating factors. Journal of Knowledge Management, 20(5), 1083-1103.

Lucena, A., \& Roper, S. (2016). Absorptive capacity and ambidexterity in R\&D: Linking technology alliance diversity and firm innovation. European Management Review, 13(3), 159-178.

Mariano, S., \& Walter, C. (2015). The construct of absorptive capacity in knowledge management and intellectual capital research: content and text analyses. Journal of Knowledge Management, 19(2), 372-400.

Martelo-Landroguez, S., \& Cegarra-Navarro, G.-J. (2014). Linking knowledge corridors to customer value through knowledge processes. Journal of KnowledgeManagement, 18(2), 342-365.

Messeni, A., Rotolo, D., \& Albino, V. (2012). The Impact of old technologies on innovation: The case of the US biotech. Industri. Technology Analysis \& Strategic Management, 24(5), 453-466.

Nieminen, H. (2005). Organizational receptivity. Understanding the interorganizational learning ability. Electronic Journal of Knowledge Management, 3(2), 107-118.

Nurcahyo, Satria Avianda, Tri Wikaningrum, 2020, Peran Knowledge Sharing, Learning Organization Dan Individual Innovation Capability Terhadap Kinerja Karyawan. Jurnal Ekonomi Dan Bisnis Vol. 21, No.2, Juli 2020 : 1 - 25. 
Ojo, AO, Raman. M., \& Chong, CW (2016). Individual differences and potential absorptive capacity in joint project teams in the Nigerian upstream oil industry. VINE Journal of Information and Knowledge Management Systems, 46(1), 45-63.

Paulsen, JM, \& Hjertø, KB (2014). Exploring individual-level and group-level levers for inter-organizational knowledge transfer. The Learning Organization, 21(4), 274-287.

Rezaei, M., \& Darwish, TK (2016). Antecedents of absorptive capacity: A new model for developing learning processes. The Learning Organization, 23(1), 77-91.

Rofiati, Tri Novianti, Angga Tri Mulyanto, 2015, Pengaruh Knpwledge Management terhadap Inovasi: Implementasi Strategi dan Kinerja Organisasi (Studi Pada RS Lavalette Malang), Jurnal Ekonomi Bisnis Tahun 20, Nomor 1, Maret 2015, hlm 1-52

Sánchez, P., Rosell, J., \& García, JM (2013). Innovation as a driver of absorptive capacity from foreign direct investment in Spanish manufacturing firms. Procedia - Social and Behavioral Sciences, 75, 236-245.

Setyowati, T., 2012, Manajemen Inovasi Berbasis Pengetahuan di Perusahaanperusahaan Kecil, Menengah, dan Besar: Survei pada Industri Barang Konsumsi di Jawa Barat, Industrial Research Workshop and National Seminar 2012 ISBN 978-979-3541-25-9, hal.418-438.

Sun, P. (2010). Five critical knowledge management organizational themes. Journal of Knowledge Management, 14(4), 507-523.

Tseng, Pai, DC, \& Hung, CH (2011). Knowledge absorptive capacity and innovation performance in KIBS. Journal of Knowledge Management, 15(6), 971-983.

Van der Heiden, P., Pohl, C., Mansor, S., \& Van Genderen, J. (2016). Necessitated absorptive capacity and metaroutines in international technology transfer: A new model. Journal of Engineering and Technology Management, 41, 65-78.

Wang,C., \& Han, Y. (2011). Linking properties of knowledge with innovation performance: the moderate role of absorptive capacity. Journal of Knowledge Management, 15(5), 802-819. 